\title{
Investigation into water retention behaviour of deformable soils
}

\author{
Simon Salager, Mathieu Nuth, Alessio Ferrari, and Lyesse Laloui
}

\begin{abstract}
The paper presents an experimental and modelling approach for the soil-water retention behaviour of two deformable soils. The objective is to investigate the physical mechanisms that govern the soil-water retention properties and to propose a constitutive framework for the soil-water retention curve accounting for the initial state of compaction and deformability of soils. A granular soil and a clayey soil were subjected to drying over a wide range of suctions so that the residual state of saturation could be attained. Different initial densities were tested for each material. The soil-water retention curves (SWRCs) obtained are synthesized and compared in terms of water content, void ratio, and degree of saturation, and are expressed as a function of the total suction. The studies enable assessment of the effect of the past and present soil deformation on the shape of the curves. The void ratio exerts a clear influence on the air-entry value, revealing that the breakthrough of air into the pores of the soil is more arduous in denser states. In the plane of water content versus suction, the experimental results highlight the fact that from a certain value of suction, the retention curves corresponding to different densities of the same soil are convergent. The observed features of behaviour are conceptualized into a modelling framework expressing the evolution of the degree of saturation as a function of suction. The proposed retention model makes use of the theory of elastoplasticity and can thus be generalized into a hysteretic model applicable to drying-wetting cycles. The calibration of the model requires the experimental retention data for two initial void ratios. The prediction of tests for further ranges of void ratios proves to be accurate, which supports the adequacy of formulated concepts.
\end{abstract}

Key words: soil-water retention curve, unsaturated soils, deformable media, constitutive modelling.

Résumé : Cet article présente une étude expérimentale et une approche de modélisation du comportement en rétention d'eau de deux sols déformables. L'objectif est d'étudier les mécanismes physiques qui gèrent les propriétés de rétention d'eau d'un sol, et de proposer une procédure constitutive pour la courbe de rétention d'eau qui considère l'état initial de compaction et la déformabilité des sols. Un sol granulaire et un sol argileux ont été soumis au séchage sur une variété de succions afin d'atteindre l'état de saturation résiduelle. Des densités initiales différentes ont été testées pour chaque matériau. Les courbes de rétention d'eau ainsi obtenues sont synthétisées et comparées en termes de teneur en eau, d'indice des vides et de degré de saturation, et sont exprimées en fonction de la succion totale. Cette étude permet d'évaluer l'effet des déformations passées et présentes du sol sur la forme des courbes. L'indice des vides exerce une nette influence sur la pression à l'entrée d'air, ce qui révèle que l'entrée d'air dans les pores du sol est plus ardue en milieu dense. Dans le plan de teneur en eau versus succion, les résultats expérimentaux démontrent le fait qu'à partir d'une certaine valeur de succion, les courbes de rétention provenant d'un même sol avec des densités différentes convergent. Les caractéristiques du comportement observées sont conceptualisées dans un modèle qui exprime l'évolution du degré de saturation en fonction de la succion. Le modèle de rétention proposé utilise la théorie de l'élastoplasticité et peut ainsi être généralisé en un modèle hystérétique applicable aux cycles de mouillage-séchage. Le calibrage du modèle nécessite des données de rétention expérimentales pour deux indices des vides initiaux. La prédiction d'essais sur des valeurs d'indices des vides plus grands est exacte, ce qui démontre que les concepts formulés sont adéquats. [Traduit par la Rédaction]

Mots-clés : courbe de rétention d'eau du sol, sols non saturés, médium déformable, modèle constitutif.

\section{Introduction}

The understanding of water retention features is an essential aspect for modelling the behaviour of unsaturated soils. It is known that the capillary properties of a soil are related to the pore volume; that is, the volume available for the fluid phases. The volume of voids in a soil depends on the granulometry and on the state of compaction of the medium. In deformable soils, it has been evidenced that the soil deformation has an effect on the shape of the soil-water retention curve (SWRC) (Romero and Vaunat 2000; Miller et al. 2002; Sugii et al. 2002; Tarantino and Tombolato 2005; Salager et al. 2007; Miller et al. 2008; Parent et al. 2011). Conventionally, the main source of deformation is the external, mechanical stress exerted on the soil. In addition, the pro- cess of drying or wetting is regarded as an additional source of deformation, indicating that the density of the soil can be strongly responsive to the suction variations (Romero 1999; Fleureau et al. 2002; Olchitsky 2002). The formulation of a general purpose water retention model should therefore account for the evolution of density or void ratio along drying and wetting processes. D'Onza et al. (2010) reviewed recent models for the SWRC featuring density-dependency. In most of the published models (Gallipoli et al. 2003; Mbonimpa et al. 2006; Nuth and Laloui 2008; Mašín 2010), the degree of saturation is linked to the void ratio through simple relationships that proved to be effective in the range of suction where capillarity predominates (low to moderate suctions). To account for the density-dependency, the following approach is used in these models: one parameter of the SWRC (for

Received 30 November 2011. Accepted 3 January 2013.

S. Salager. Grenoble-INP, UJF-Grenoble 1, CNRS UMR 5521, 3SR Lab, Grenoble F-38041, France.

M. Nuth. Department of Civil Engineering, Université de Sherbrooke, 2500 Boul. Université, Sherbrooke, QC J1K 2R1, Canada.

A. Ferrari and L. Laloui. Laboratory for Soil Mechanics, Ecole Polytechnique Fédérale de Lausanne, Station 18, CH-1015 Lausanne, Switzerland.

Corresponding author: Simon Salager (e-mail: simon.salager@hmg.inpg.fr). 
instance the air-entry value) is made to depend on the void ratio according to a linear relationship or a power law. The calibration of the density-dependency is thus straightforward. The shortcoming of this type of approach is that the air-entry value that is the coupling parameter belongs to the capillary domain of suction. At relatively high suctions (low degrees of saturation), i.e., in the osmotic domain of suction, the air-entry value is no longer a representative coupling parameter, which may result in a less accurate prediction of the degree of saturation. Tarantino (2009) proposed a void ratio-dependent model for the water retention curve such that the water retention curves should converge to a single equation in the high suction range where the water retention data are little affected by the void ratio. Thus, the amplitude of the coupling between the soil deformation and the SWRC may be different in the capillary and osmotic regimes of suction. Similarly, in structured materials with double porosity, the SWRC may react differently to the change of volume in macropores than that in micropores. It is therefore proposed here to characterize systematically the shape of the SWRC from full saturation down to residual saturation in some representative deformable media.

The analysis presented in the paper is twofold. On one hand, an experimental study was carried out on two different deformable soils: a clayey sand (called clayey silty sand) from the south of France and a compacted scaly clay originating from Sicily. The materials were subjected to drying using combined techniques of suction control to cover a high range of suction (up to $300 \mathrm{MPa}$ ) and reach low degrees of saturation (less than 0.1). The experimental program enabled the investigation of trends in the retention behaviour in terms of water content and void ratio, as well as degree of saturation. In the interpretation of the SWRCs obtained, emphasis is laid on the initial density and the volume change of the specimens during the tests. On the other hand, the observed features of behaviour are conceptualized into a model of the degree of saturation as a function of suction and deformation. The proposed elastoplastic retention model accounts for the initial compaction and the density variations due to suction change.

\section{Experimental determination of the SWRCs}

To encompass a large range of retention properties of soils, the present study consists of two different types of soil, namely a clayey silty sand and a cohesive clayey soil.

\section{Experimental results for granular soil}

A clayey silty sand was used in the preparation of samples representative of a granular soil (Salager 2007), as described in this section. This soil is classified as SC-CL according to the Unified Soil Classification System (USCS; ASTM 2006).). The liquid and plastic limits are $25 \%$ and $14.5 \%$, respectively. Sand, silt, and clay fractions are $72 \%, 18 \%$, and $10 \%$, respectively. The clay fraction consists mainly of smectite, chlorite, and phyllite. The optimum water content is $14.5 \%$ at a dry density, $\rho_{\mathrm{d}}$, equal to $1860 \mathrm{~kg} \cdot \mathrm{m}^{-3}$. The specific gravity is $G_{\mathrm{s}}$ equal to 2.65 .

The experimental program involves five series of samples compacted at five different densities (moulding states in Table 1 and Fig. 1), ranging from 1350 to $1950 \mathrm{~kg} \cdot \mathrm{m}^{-3}$. To prepare the samples, the soil was air-dried until no significant changes in water content were observed and was later passed through a $2 \mathrm{~mm}$ sieve. Then, it was mixed with demineralized water to reach the target water content and was placed in airtight boxes for at least $48 \mathrm{~h}$ to allow the water content to homogenize within the material. Each sample was compacted statically in a single layer $(30 \mathrm{~mm}$ diameter and $10 \mathrm{~mm}$ high) to the target initial dry density. Finally, the samples were placed on the porous ceramic of a pressure plate apparatus and saturated by imbibition. Characteristics after saturation are reported in Table 1 (initial states). Volume changes at the end of the saturation phase were monitored using a fluid displacement technique that uses pycnometers filled with Kerdane
Table 1. Moulding and initial states of clayey silty samples.

\begin{tabular}{llllllll}
\hline & \multicolumn{3}{l}{ Moulding states } & & \multicolumn{3}{l}{ Initial states } \\
\cline { 2 - 3 } Series & $e$ & $\rho_{d}\left(\mathrm{~kg} \cdot \mathrm{m}^{-3}\right)$ & $w(\%)$ & & $e$ & $\rho_{d}\left(\mathrm{~kg} \cdot \mathrm{m}^{-3}\right)$ & $w(\%)$ \\
\hline 1 & 0.96 & 1350 & 18 & & 1.01 & 1319 & 38.1 \\
2 & 0.77 & 1500 & 18 & & 0.86 & 1427 & 32.3 \\
3 & 0.61 & 1650 & 18 & & 0.68 & 1575 & 25.7 \\
4 & 0.47 & 1800 & 14 & & 0.55 & 1708 & 21.0 \\
5 & 0.36 & 1950 & 12 & & 0.44 & 1845 & 16.5 \\
\hline
\end{tabular}

Fig. 1. Moulding and initial states for clayey silty samples.

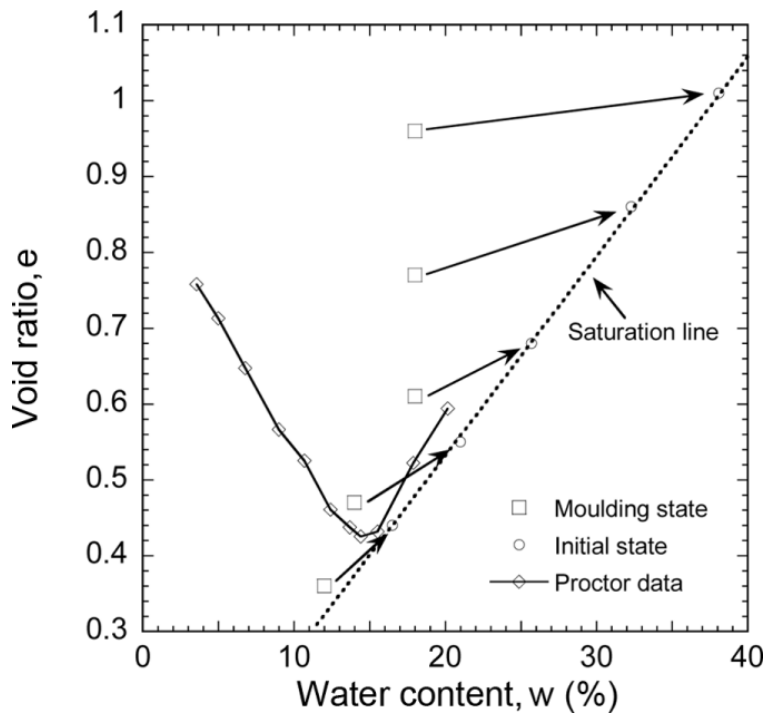

(Péron et al. 2007). All samples reached a degree of saturation greater than $99 \%$.

To obtain the retention curves of the soil in a wide range of suctions, two techniques of suction control were used. Concerning the lower suction values, from 1 to $1000 \mathrm{kPa}$, the axis translation technique was used in a pressure plate apparatus. For the higher suctions comprising suctions between 4 and $326 \mathrm{MPa}$, suction was applied by means of the vapour equilibrium technique in desiccators (Salager et al. 2011).

For each series, 16 to 18 suction values were imposed to determine the main drying paths. At equilibrium, the water content and the void ratio of the samples were measured for each suction value. The points represented in Fig. 2 are average values over three samples for each test. The obtained standard deviation for each dataset $i$ is lower than 0.015 for both the void ratio and the water content.

Figure $2 a$ depicts the points obtained for the five sample series in terms of water content versus matric suction. Due to the logarithmic scale axis, the dots plotted for a suction of $0.01 \mathrm{kPa}$ correspond to saturation states (no suction). These points lead to the definition of the water retention curves of the clayey silty sand compacted at five different initial void ratios, $e_{0}$. For each series, the water content variations are very limited for the low suction values (lower than 1 to $5 \mathrm{kPa}$ ) while they are significant in the intermediate suction range (5 $\mathrm{kPa}$ up to $3000 \mathrm{kPa}$ ). Interestingly, for suction values higher than $200 \mathrm{kPa}$, the initial void ratio no longer has influence and the relationship between water retention and suction can be considered as unique.

Figure $2 b$ presents the obtained results in the plane of void ratio versus suction. The curves describe the consolidation induced by drying that can also be called suction-loading. According to the changes in void ratio upon suction increase, the curves may be divided into three main parts. For low suction values (lower than 
Fig. 2. (a) Water content versus applied suction for clayey silty samples prepared at different initial void ratios; $(b)$ variation of void ratio under suction loading for five densities of granular soil.
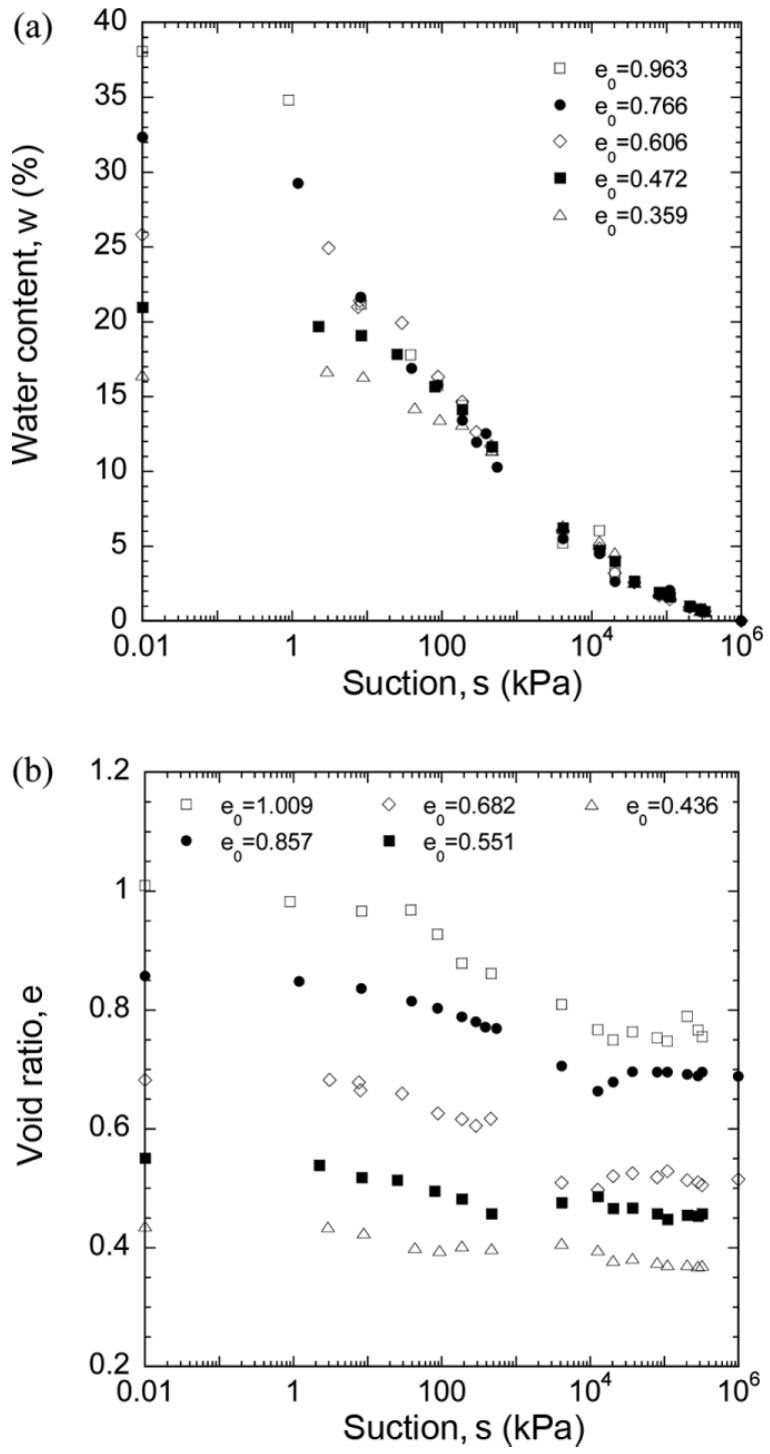

1 to $5 \mathrm{kPa}$ ), a very small evolution of the density is noted with respect to the suction; this circumstance can be explained by considering that the capillary forces between grains are too low to induce granular re-arrangement. For the intermediate suction values (5 $\mathrm{kPa}$ up to $3000 \mathrm{kPa}$ ) the suction loading leads to a remarkable decrease of the void ratio; these variations are in the range from 0.06 (for the series corresponding to the lowest initial void ratios) to 0.2 (for the series corresponding to the highest initial void ratios). For the high suction values, in this type of soil, the water is present mainly in an adsorption form and the capillary effects are less significant (Salager et al. 2010).

\section{Experimental results on a clayey soil}

The compacted scaly clay was used to determine the SWRC of a cohesive material. The soil is a kaolinitic-illitic clay with a liquid limit, $w_{1}=58 \%$; a plasticity index, $I_{\mathrm{p}}=30 \%$; and a classification of $\mathrm{CH}$ according to the USCS. This material was used, successfully, for the core of two dams built in Sicily (Italy). The specimens were obtained by dynamically compacting clay lumps that were partially disaggregated (passing them through a $4.25 \mathrm{~mm}$ sieve), previously air-dried, and subsequently prepared to target water content values (Ferrari 2007). The compaction took place on the dry side of optimum, providing specimens that are characterized by a double-structured microfabric arrangement (Airò Farulla et al. 2010). The effect of suction variations on the volumetric behaviour at the microstructural level was examined using environmental scanning electron microscopy (ESEM) photomicrographs (Airò Farulla et al. 2010). The microstructural level (porosity within clay assemblages) showed good reversibility upon suction variation; the maximum volumetric deformation for the microstructural level was approximately $3.5 \%$ for a complete wetting-drying episode.

Different initial conditions in terms of void ratio and degree of saturation were obtained by varying the initial water content and the compaction energy. As in the case of the clayey silty sand, to cover a wide range of suctions, different techniques to control and to measure suction were employed. For values up to $800 \mathrm{kPa}$, experimental results were obtained by means of the axis translation technique in a controlled-suction oedometric cell. The samples were subjected to a drying path starting from a saturated state. The measurement of water volume exchanges and specimen volume changes allowed to completely define the retention behaviour along the main drying curve. In fact, the volume of water expelled from the sample can be measured as long as water exchange takes place through the liquid phase that is continuous. To collect information for lower values of the degree of saturation, suction was measured, by means of two psychrometers (Cardoso et al. 2007), on specimens that were left to air-dry for a controlled time and were subsequently isolated to allow the water content to equalize within the specimens. In this case, suction was obtained by the measurement of the relative humidity of the pore air, and the total suction had to be invoked. For the specimens left to air-dry, volume variations were monitored using a precision digital micrometer. Changes in volume were negligible for total suction values higher than $8 \mathrm{MPa}$; the corresponding water content value (0.015) agrees well with the shrinkage limit of the material. Finally, a collection of triplets (suction, degree of saturation, and void ratio) were gathered.

To show the effect of density on the retention behaviour, two equivalent retention curves at different void ratios ( 0.45 and 0.55 ) were drawn. Selected void ratios correspond roughly to the average void ratio measured in situ during the construction of the mentioned dams and to the optimum value for the Modified Proctor compaction test. The approach is to identify, within the array of points, those with a void ratio close to the chosen target values and belonging to main drying episodes. The obtained retention curves are reported in Fig. 3, both in terms of degree of saturation and water content versus suction. The evolution of the degree of saturation with suction (Fig. $3 a$ ) shows that the denser the material gets, the higher the air-entry value (suction from which air starts to enter into pores) rises. At a suction of $300 \mathrm{kPa}$, the degree of saturation is still almost equal to one when the void ratio is 0.45 . Furthermore, when observing the retention curves in terms of water content (Fig. 3b), the plots show that beyond a water content of approximately 0.11 the effect of the void ratio becomes negligible in the general trend of the retention curves.

\section{Behavioural features of water retention}

Even though the tested materials are of different types, some common conclusions may be drawn on the basis of the previous experimental results. First, one can notice that the air-entry value is the parameter of the water retention curve that is most influenced by density. For both granular and clayey materials, Figs. 2 and 3 show that the air-entry value increases with a decrease of void ratio. This result corroborates the trend drawn by several authors (Vanapalli et al. 1999; Kawaï et al. 2000; Verbrugge and Fleureau 2002; Zhou and Yu 2004).

If suction loading is applied to an unsaturated soil, the migration of the liquid phase will initiate once the air-entry value is 
Fig. 3. Water retention curves of compacted clayey soil: (a) degree of saturation and $(b)$ water content versus suction.
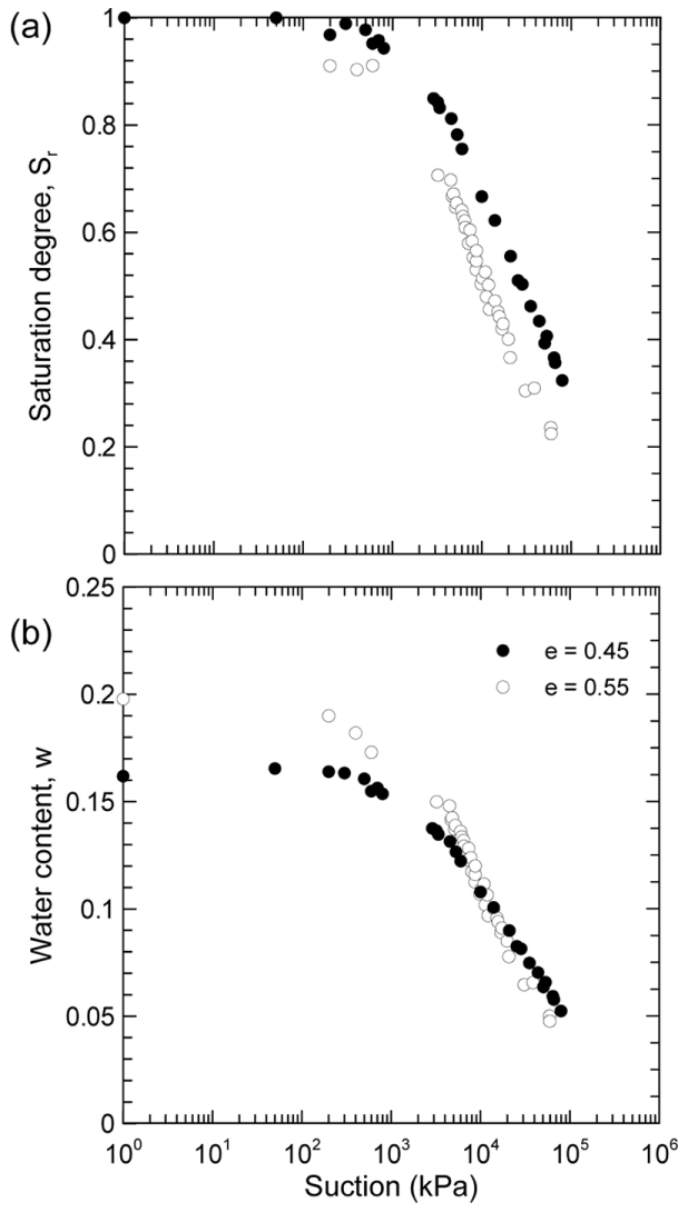

overcome; this transition in water retention behaviour reflects a limit level of capillary tension that can be sustained by the soil. This limit varies conversely with the size of the pores and thus with the void ratio, and is the reason why the air-entry value decreases notably when the void ratio increases.

To take into account this coupling between water retention behaviour and density, Nuth and Laloui (2008) proposed a model in which the air-entry value $s_{\mathrm{eH}}$ is a function of the skeleton volume information. The proposed explicit expression is the following linear approximation:

$$
s_{\mathrm{eH}}=s_{\mathrm{e}}+\pi_{\mathrm{H}} \varepsilon_{\mathrm{v}}
$$

where $s_{\mathrm{e}}$ is the reference air-entry value, $\pi_{\mathrm{H}}$ is a material parameter, and $\varepsilon_{\mathrm{v}}$ is the volumetric strain.

Equation [1] has the advantage of being easy to calibrate because only one parameter is needed besides the reference air-entry value, which is a parameter with a physical meaning. As a model parameter, the air-entry value also has the advantage of being well documented, even in geotechnical studies where no complete SWRC is available. Moreover, the function (eq. [1]) showed its predictive power for a wide range of materials. Consequently, this linear approximation will be integrated into the model to be developed further in the present study.

In eq. [1], the volumetric strain, $\varepsilon_{\mathrm{v}}$, is the coupling parameter between the mechanical stress-strain behaviour and the SWRC. The volumetric strain is a direct measure of the pore space and thus of the water retention capability. Any increase in the overburden or confining stress in a soil leads to an increase in the volumetric strain. According to eq. [1], the air-entry value should thus be higher at higher stresses, which is in agreement with the common observation that soils undergoing a higher confining stress have a lower desorption rate. The volumetric strain (or void ratio) is the most relevant coupling variable as it accounts for the complete mechanical stress-strain history of the material including plastic-hardening. Consequently, the performance of a straindependent water retention model depends on the accuracy of the volume change information and (or) the performances of the mechanical stress-strain model.

In the experimental results presented, the plane of water content versus suction showed another important aspect of the water retention behaviour. At a certain suction value, the water retention curves determined at different densities converge in a single curve that remains unique for high suctions. The experimental evidence shows that the influence of the void ratio is no longer visible beyond suctions in the range from 100 to $200 \mathrm{kPa}$ for the clayey silty sand, and beyond suctions of $5000 \mathrm{kPa}$ for the clayey material. The origins of the convergence of the water retention curves have a different explanation in granular and clayey materials.

In the granular material, the network of pores consists of large and small pores. Large pores are easily collapsed under the effect of a load while microscopic pores need much higher stress to be reduced. The thinnest part of the pore network could even be considered as incompressible unless grain-crushing occurs (Fredlund and Pham 2007). So, the total volume change of the granular medium essentially equals the volume change of the large pores. The latter may be induced by a mechanical load such as the static compaction used during the sample fabrication or by suction loading (Cusinier and Laloui 2004). The SWRC, which reflects the arrangement and size of pores, is thus more likely to vary from a dense sample to a looser sample in the low suction range where the material is more compressible.

Regarding the clayey material, two zones can be defined on the SWRC. The first zone corresponds to the interaggregate porosity and the second zone corresponds to the intraaggregate porosity (Romero and Vaunat 2000; Koliji et al. 2006). Only low suctions can develop in the interaggregate porosity and the effects of hydromechanical couplings are important in this zone. In the second zone, corresponding to high suctions, the water retention curve is less dependent on the mechanical aspects and notably less dependent on void ratio. This observation is corroborated by the experimental tests performed by Vanapalli et al. (1999), which show that the water retention curve of a clayey sand is independent of the mechanical history in the range of high suctions. Romero et al. (2011) proposed to relate the point at which the curves converge to the evolution of the microfabric arrangement of the clayey material in hydromechanical processes.

For the results considered, in terms of modelling, this convergence point in the plane of water content versus suction (with the coordinates $\left.\left(s_{\text {conv }}, w_{\text {conv }}\right)\right)$ is assumed as unique and independent of the density. This convergence point can be translated in the plane of degree of saturation, $S_{\mathrm{r}}$, versus suction by the following relation:

[2] $\quad S_{\mathrm{r}}=\frac{w_{\text {conv }} G_{\mathrm{s}}}{e}$

where $G_{\mathrm{s}}$ is the specific density.

\section{Modelling framework for retention curves}

In light of the features of retention behaviour presented above, a modelling framework is formulated. The proposed concept is based on a published model, named Advanced Constitutive Model for Environmental Geomechanics (ACMEG-s, Nuth and Laloui 2008; Nuth et al. 2010). As discussed previously, several of the 
parameters of the ACMEG-s have a physical meaning and are straightforward to calibrate. One of these is the air-entry value, which is additionally an important variable to be exchanged with a mechanical stress-strain model for unsaturated soils. The model also features both the void ratio dependency and the hysteresis in the SWRC. As the reference model ACMEG-s comprehends the capillary hysteresis, it will be a built-in feature of the present, updated model. However, given the fact that the experimental studies presented consist of drying paths exclusively (monotonic loading), the capillary hysteresis is beyond the scope of this paper and the focus of the study is on the mere effects of void ratio on the shape of the SWRC. The changes of degree of saturation are modelled as either reversible or dissipative, as in the reference model, where elastoplasticity is used to account for the capillary hysteresis. The increment of degree of saturation $\mathrm{d} S_{\mathrm{r}}$ is thus decomposed into an elastic part, $\mathrm{d} S_{\mathrm{r}}^{\mathrm{e}}$, and a plastic part, $\mathrm{d} S_{\mathrm{r}}^{\mathrm{p}}$ :

[3] $\quad \mathrm{d} S_{\mathrm{r}}=\mathrm{d} S_{\mathrm{r}}^{\mathrm{e}}+\mathrm{d} S_{\mathrm{r}}^{\mathrm{p}}$

Originally the decomposition of eq. [3] is justified essentially by the need for describing the scanning lines, which are the unloadingreloading lines during drying-wetting cycles (Viaene et al. 1994). Aside from the scanning lines, eq. [3] will help to improve the quantitative response of the model in the neighbourhood of the air-entry value.

For better understanding, it is provisionally assumed that the void ratio remains perfectly constant during a drying path. In the plane of degree of saturation versus suction (Fig. 4a), the model for the SWRCfeatures four main domains of behaviour that are also noticeable in the plane of water content versus matric suction (Fig. 4b). Starting with fully saturated conditions, the degree of saturation remains equal to 1 for suctions that are lower than the air-entry value $s_{\mathrm{eH}}$ (domain (a)). Beyond this value of suction limit, air can break into the pore space and the saturation level decreases, first moderately (domain (b)) and then more rapidly as suction continues to increase (domain (c)).

In domain (b), the increment of degree of saturation is elastic and equal to

[4] $\quad \mathrm{d} S_{\mathrm{r}}^{\mathrm{e}}=\frac{\mathrm{d} s}{K_{\mathrm{H}}\left(s / s_{\mathrm{eH}}\right)}$

where $K_{\mathrm{H}}$ is the elastic modulus and $s$ is suction.

The "drying yield suction" $s_{\mathrm{D}}$ is defined as the limit between domains (b) and (c) in Fig. 4a. It is the main parameter of the yield surface that is defined as

$$
\begin{aligned}
f=\| \ln (s)-\ln \left(s_{\mathrm{D}}\right)+\frac{1}{2}\left[\ln \left(s_{\mathrm{D} 0}\right)-\right. & \left.\ln \left(s_{\mathrm{eH}}\right)\right] \| \\
& -\frac{1}{2}\left[\ln \left(s_{\mathrm{D} 0}\right)-\ln \left(s_{\mathrm{eH}}\right)\right]
\end{aligned}
$$

where $s_{\mathrm{D} 0}$ is the initial value of the drying yield suction.

The function $f$ in eq. [5] defines a kinematic yield surface that is valid for both drying and wetting processes. The aperture of the capillary hysteresis equals twice the kinematic radius (i.e., $2 \times$ $\left.(1 / 2)\left[\ln \left(s_{\mathrm{DO}}\right)-\ln \left(s_{\mathrm{eH}}\right)\right]\right)$. In domain $(\mathrm{c})$, the threshold $s_{\mathrm{D}}$ evolves with the history of suction, from the initial value $s_{\mathrm{D} 0}$, and pilots irreversible changes in the degree of saturation:

[6] $\ln \left(\frac{s_{\mathrm{D}}}{s_{\mathrm{D} 0}}\right)=\beta_{\mathrm{H}} S_{\mathrm{r}}^{\mathrm{p}}$

where $\beta_{\mathrm{H}}$ is the coefficient of compressibility for the plastic part of degree of saturation, $S_{\mathrm{r}}^{\mathrm{p}}$.
As explained later, the coefficient of plastic compressibility defined in eq. [6] is fully determined via the model parameters and does not need to be calibrated.

The model response in domain (d) (Fig. 4a) needs to be addressed from the viewpoint of the water content, $w$, versus suction, $s$, plane (Fig. 4b). As mentioned previously, a convergence point is identified at the suction $s_{\text {conv }}$. Beyond this value, all the water retention curves in plane $(w$-lns) converge into a unique curve, assumed here to be a straight line in logarithmic scale up to the maximum suction, $s_{\max }$, which is a material parameter. The shape of the retention curves in terms of degree of saturation is thus deduced from planes $(w-\ln s),(e-\ln s)$, and eq. [2].

The effect of void ratio is introduced via the dependency law of the updated air-entry value $s_{\mathrm{eH}}$ presented in eq. [1], which can be also written as

[7] $s_{\mathrm{eH}}=s_{\mathrm{e}}+\pi_{\mathrm{H}}\left(\frac{e-e_{0}}{1+e_{0}}\right)$

with $e_{0}$ being the reference void ratio, $s_{\mathrm{e}}$ the air-entry value at this reference void ratio, and $\pi_{\mathrm{H}}$ a material parameter. The relationship in eq. [7] has been validated by Nuth and Laloui (2008) on a number of fine-grained materials. It is consistent with the previous observations evidencing an increase in the air-entry value for denser states in silty sand and clay.

If the change in void ratio has a direct effect on the air-entry value $s_{\mathrm{eH}}$, it also indirectly affects the complete shape of the retention curve. In conformity with the usual shape of the capillary hysteresis, it can be assumed that the main drying curve is parallel to the main wetting curve within the range of suction where hysteresis occurs. It is thus assumed that the size of the reversible domain in plane $\left(S_{\mathrm{r}}-s\right)$ remains constant; that is to say, that whatever the void ratio, the width of domain (b) in Fig. $4 a$ is unchanged (see paths $\mathrm{AB}$ and $\mathrm{A}^{\prime} \mathrm{B}^{\prime}$ ). This implies the following condition on the initial yield suction $s_{\mathrm{D} 0}$ :

[8] $\quad s_{\mathrm{D} 0}=\frac{s_{\mathrm{DI}} s_{\mathrm{eH}}}{s_{\mathrm{e}}}$

where $s_{\mathrm{DI}}$ is the initial yield suction corresponding to the void ratio of reference $e_{0}$.

Supposing at first that no deformation occurs during the drying process; the modelled retention curves of two samples at different initial void ratios, $e_{0}$ and $e_{1}$, can be compared (solid thick lines and dotted lines, respectively, in Fig. 4). Provided that $e_{1}$ is lower than $e_{0}$, the corresponding air-entry suction for sample 1 (point $\mathrm{A}^{\prime}$, Fig. $4 a$ ) is greater than that of the reference sample (point A). The drying yield suction corresponding to $e_{1}$ (point $\mathrm{B}^{\prime}$ ) is also greater than the reference drying yield suction measured at $e_{0}$ (point $\mathrm{B}$ ). Beyond the drying yield suction, for constant void ratios, the response to suction change in terms of degree of saturation is a straight line until reaching the suction of convergence (points $\mathrm{C}$ and $C^{\prime}$ in plane). Consequently, the coefficient $\beta_{\mathrm{H}}$ depends on the void ratio. In domain (d), the degree of saturation is calculated on the basis of the water content and void ratio.

The main concern of this paper is the understanding of the retention behaviour of deformable materials; that is to say, soils that evidence changes in void ratio not only due to mechanical loading, but also during drying and wetting processes. In those types of soils, the assumption that a void ratio remains equal to its initial value during drying does not hold. Figure $4 c$ gives the typical qualitative volumetric response of the skeleton for these soils (solid gray line), starting with an initial void ratio $e_{0}$ in the saturated conditions and ending with a final void ratio $e_{1}$ at high suctions. 
Fig. 4. Conceptual representations of proposed retention model: (a) degree of saturation, $(b)$ water content, and $(c)$ void ratio versus matric suction.

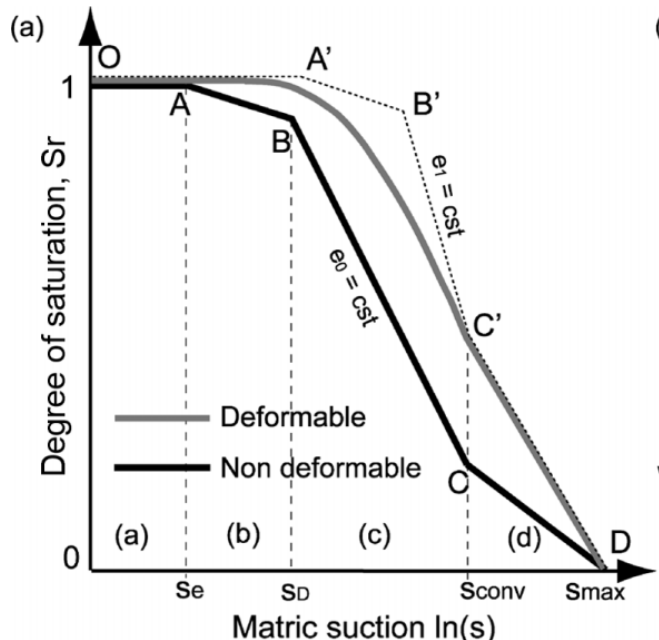

(c)

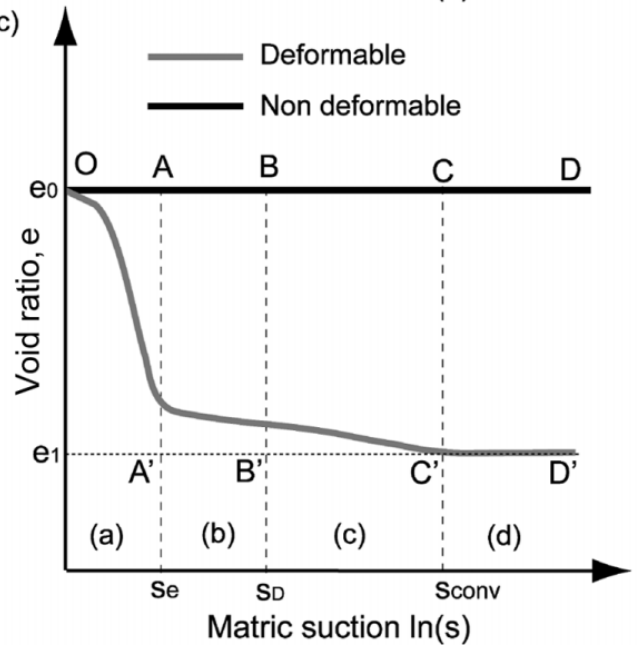

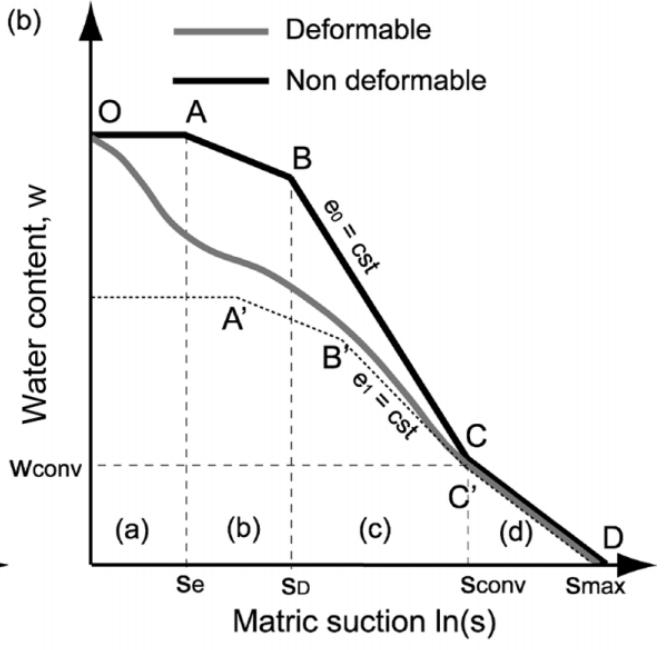

Due to eq. [7], any change in void ratio will cause an update of the air-entry value, which in turn will affect the drying yield suction (eq. [8]). As a consequence, the whole retention curve in the plane $\left(S_{\mathrm{r}}-s\right)$ is shifted to the right, while the suction of convergence, $s_{\text {conv }}$, is not affected. The solid gray line in Fig. $4 a$ shows that the degree of saturation will, as a result, evolve nonlinearly with lns, which is necessary to join points $A$ and $C^{\prime}$. The deformable SWRC can thus be drawn by making the point $\left(S_{\mathrm{r}}-s\right)$ jump from one retention curve drawn at a constant void ratio to the other. In the case of Fig. 4, this array of curves is bound by the two curves obtained at constant void ratios $e_{0}$ and $e_{1}$.

The prediction quality of the degree of saturation will thus depend on the accuracy of the void ratio evolving with suction. The proposed water retention model consequently needs to be coupled with a stress-strain model for unsaturated soils. An appropriate constitutive mechanical framework shall be elastoplastic and account for the suction effects on the stress-strain response (e.g., D'Onza et al. 2010; Nuth et al. 2010). As it is not the scope of this paper to describe a stress-strain model for unsaturated soils, it is proposed to decouple the mechanical model from the present conceptual framework. Hence, the void ratio is hereafter uniquely considered as an input for the model of retention. To avoid justifying and discussing the parameter determination of any given stress-strain model, the experimental data of void ratio versus suction will be directly used in the following as the required input.
In total, seven model parameters are necessary for the calibration of the constitutive model presented. It is noted that most of the parameters are inherited from the reference constitutive model ACMEG-s by Nuth and Laloui (2008), in which a total of six parameters are necessary to account for the following physical mechanisms:

- Density-dependent air-entry value.

- Capillary hysteresis (definition of a main drying curve and a main wetting curve).

- Occurrence of scanning lines.

- Occurrence of a residual degree of saturation.

The present formulation enables to keep all of the above features of behaviour comprehended by the reference ACMEG-s, and to add the ability to reproduce the convergence of the retention curves at high suctions. Some parameters of the present model replace the ones in the ACMEG-s, but only one supplementary parameter suffices to include the capability of convergence.

\section{Simulations}

The experimental results presented previously are used as a reference to assess the capabilities of the proposed modelling framework. The aim is to validate the concepts and to formulate recommendations for further advanced modelling of the retention curve. The numerical results are issued from (i) the calibration of the reference 
Table 2. Material parameters used for simulations of granular soil.

\begin{tabular}{lllllll}
\hline$s_{\mathrm{e}}(\mathrm{Pa})$ & $K_{\mathrm{h}}(\mathrm{Pa})$ & $s_{\mathrm{DI}}(\mathrm{Pa})$ & $\pi_{\mathrm{H}}(\mathrm{Pa})$ & $s_{\text {conv }}(\mathrm{Pa})$ & $w_{\text {conv }}$ & $s_{\max }(\mathrm{Pa})$ \\
\hline $1 \times 10^{2}$ & $33 \mathrm{~Pa}$ & $1 \times 10^{3} \mathrm{~Pa}$ & $-4.8 \times 10^{4} \mathrm{~Pa}$ & $1.3 \times 10^{6} \mathrm{~Pa}$ & 0.075 & $4 \times 10^{8} \mathrm{~Pa}$ \\
\hline
\end{tabular}

Fig. 5. Simulation of retention behaviour of clayey silty sand: $(a)$ calibration of parameter $\pi_{\mathrm{H}}$; $(b)$ evolution of degree of saturation versus void ratio at suction of convergence; $(c)$ modelled retention behaviour: degree of saturation versus suction; $(d)$ modelled retention behaviour: water content versus suction.
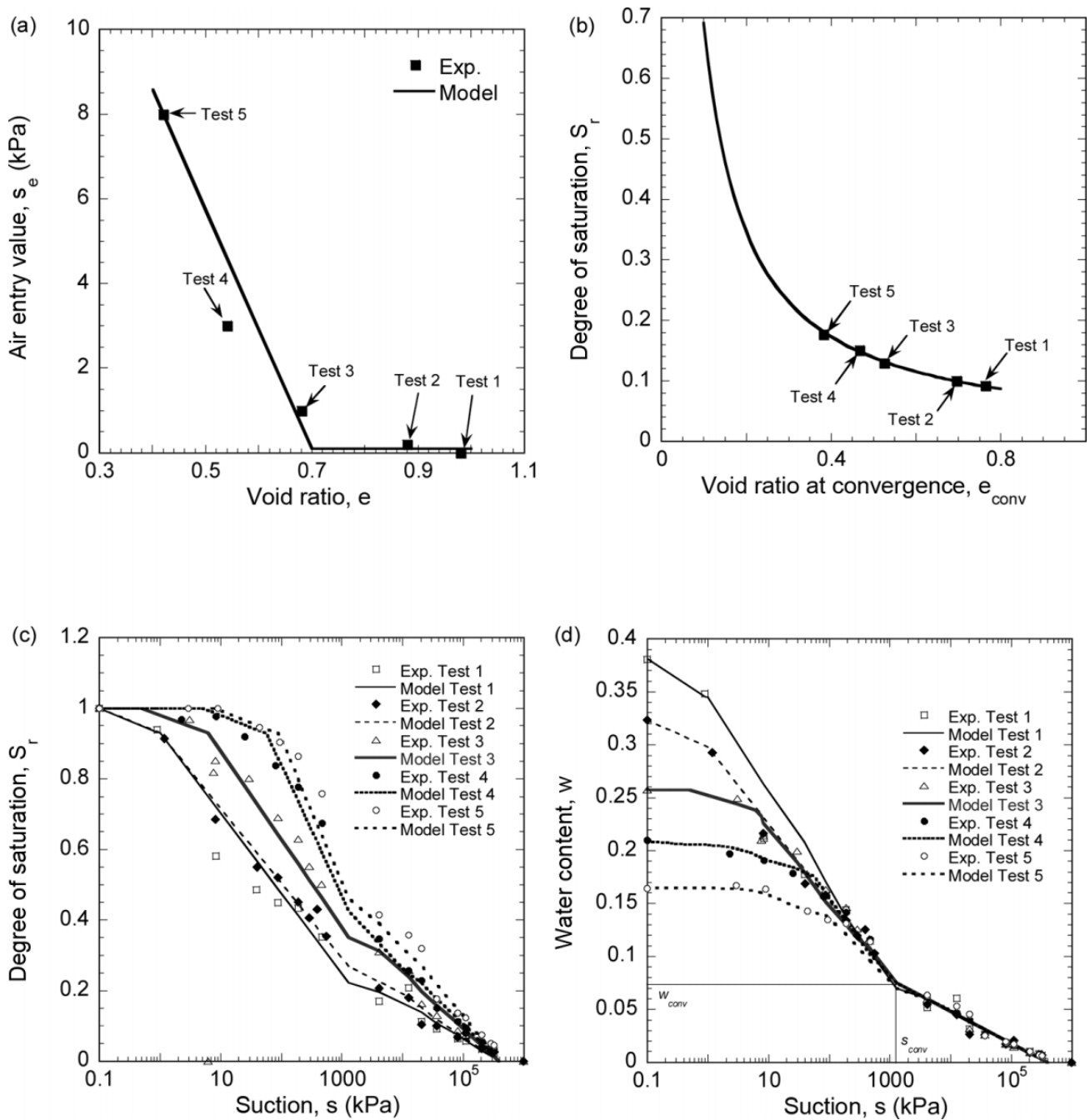

retention curve at the given void ratio for each dataset and (ii) the prediction of the water retention curves at lower void ratios.

Starting with the clayey silty sand soil, the material parameters are summarized in Table 2 . They are calibrated on the basis of the retention curve determined for a reference void ratio of $e=0.7$ with the following procedure:

1. The reference air-entry value, $s_{\mathrm{e}}$, is first determined.

2. The coefficient of coupling $\pi_{\mathrm{H}}$ is fitted with the help of a second air entry value.

3. The reversible slope is $K_{\mathrm{H}}$-fitted.

4. The drying yield suction, $s_{\mathrm{DI}}$, is calibrated.

5 . The point of convergence ( $s_{\text {conv }}, w_{\text {conv }}$ is determined.

6. The maximum suction, $s_{\max }$, is then adjusted

The calibration of the term of coupling, $\pi_{\mathrm{H}}$, is plotted in Fig. $5 a$. The increase in air-entry value with void ratio is fairly reproduced by the model, indicating that the linear approximation is acceptable. Provided that the air-entry value is a physical parameter, it is

established that the suction of air entry cannot be negative. The function plotted in Fig. $5 a$ therefore reaches a plateau (minimum value) for void ratios greater than 0.7 . The plane $\left(S_{r}-e_{\text {conv }}\right)$ is also of interest (Fig. $5 b$ ), as it evidences the nonlinearity of the relationship between the degree of saturation and the void ratio at the suction of convergence. The modelled degree of saturation (Fig. $5 c$ ) is more particularly accurate for lower void ratios (e.g., tests 3,4 , and 5). The predicted water contents are satisfactory both in the zone of low suction and beyond the suction of convergence (Fig. $5 c$ ). It may be noticed that the calibration of parameter $s_{\text {conv }}$ has an important effect on the quality of the prediction in plane $(w-\ln s)$. In the present case, the maximum suction $s_{\max }$ could be calibrated either in the plane $(w-\ln s)$ or $\left(S_{\mathrm{r}}-\ln s\right)$, as all the retention curves remarkably reach a quasi-nil water content and degree of saturation for a suction of $400 \mathrm{MPa}$.

Provided that the air-entry value is void ratio-dependent, the variable $e$ must be known anytime. As mentioned earlier, it is not the scope of the paper to present a constitutive model for the me- 
Table 3. Material parameters used for simulations of compacted clay.

\begin{tabular}{lllllll}
\hline$s_{\mathrm{e}}(\mathrm{Pa})$ & $K_{\mathrm{h}}(\mathrm{Pa})$ & $s_{\mathrm{DI}}(\mathrm{Pa})$ & $\pi_{\mathrm{H}}(\mathrm{Pa})$ & $s_{\text {conv }}(\mathrm{Pa})$ & $w_{\text {conv }}$ & $s_{\max }(\mathrm{Pa})$ \\
\hline $1.08 \times 10^{5}$ & 15 & $1.44 \times 10^{6}$ & $-2.67 \times 10^{6}$ & $1.13 \times 10^{7}$ & 0.102 & $4.5 \times 10^{8}$ \\
\hline
\end{tabular}

Fig. 6. Simulation of retention behaviour of compacted clayey soil: (a) modelled retention behaviour: degree of saturation versus suction; (b) modelled retention behaviour: water content versus suction and evolution of void ratios.
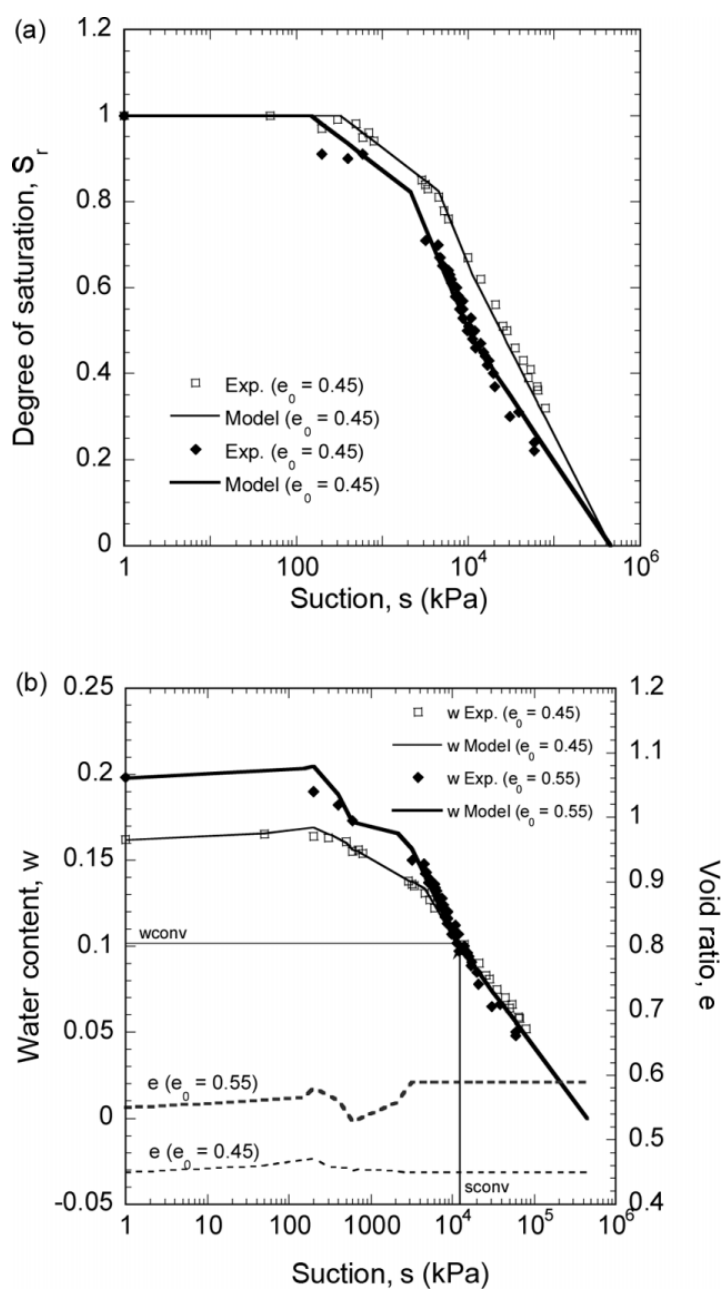

chanical behaviour. Therefore the experimental void ratios have been taken directly into consideration for the calculations (Fig. 2). Due to the scattered void ratios in the domain $s \geq s_{\text {conv }}$, the prediction of the degree of saturation is not linear in the $\left(S_{\mathrm{r}}-\ln s\right)$ plane (Fig. $5 c$ ).

Following the same procedure, the parameters of the water retention model have been calibrated for the second case study of the compacted clayey soil (Table 3). The void ratio of reference has been taken equal to the maximum void ratio measured experimentally; that is, 0.59 . With only two experimental retention curves, the calibration of the air-entry value as a function of void ratio is straightforward. The parameter $s_{\max }$ had to be interpolated from Fig. $3 b$ by estimating the suction at which zero water content should be reached. The experimental retention results by Romero (1999) on compacted clay, using the vapour equilibrium technique for high suctions, show that in such materials $s_{\max }$ should be greater than $200 \mathrm{MPa}$. Figure $6 a$ shows that the model fits the experimental points accurately enough, and captures the various slope changes in the plane $\left(S_{\mathrm{r}}-\ln s\right)$. In the complementary plane of water content versus suction (Fig. 6b), the water content
Fig. 7. Simulation of complete drying-wetting cycle on compacted clayey soil.

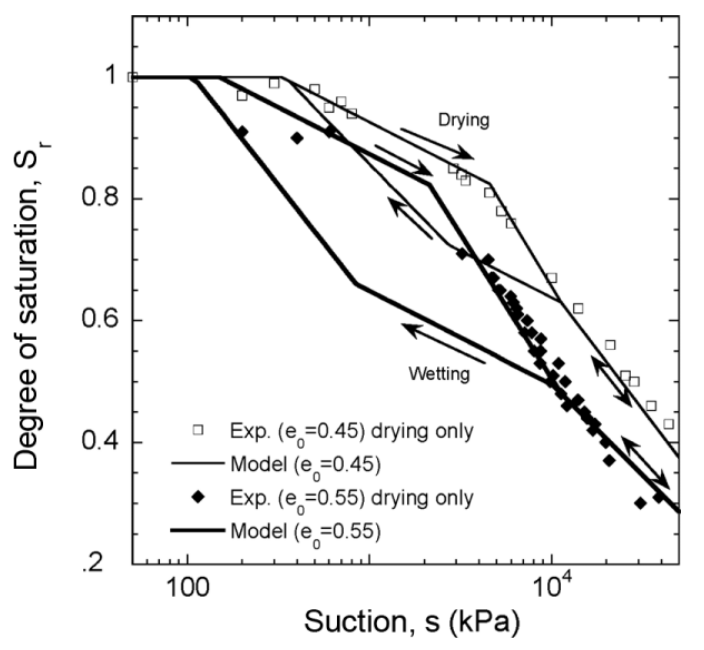

is slightly overestimated for the case $e_{0}=55$ for suctions lower than the air-entry value. This unexpected variation of the predicted water content is due to the sudden variations in the void ratio in this range of suctions (Fig. 6b). Indeed, the real void ratios have been used here for the calculation of the water contents, which can be easily identified in Fig. $6 b$ by comparing the variation of void ratio with the variation in water content. Overall, the model response is satisfactory in both $\left(S_{\mathrm{r}}-\ln s\right)$ and $(w-\ln s)$ planes, with a consistent description of the air-entry values and behaviour in the zone of convergence.

Although no experimental data were obtained along wetting paths for the two tested materials, the response of the model was tested against a complete drying-wetting cycle using the parameters of the compacted-clayey soil (Table 3). Figure 7 illustrates the main wetting curves that were obtained for the two tests $\left(e_{0}=45\right.$ and $\left.e_{0}=55\right)$. The SWRCs obtained along drying are the exact same curves as in previous Fig. $6 a$, but the horizontal and vertical scales were changed to better evidence the capillary hysteresis. During the wetting process, the void ratio is required. It was assumed in the calculations that the void ratio kept its last value reached at the end of the drying process, $e_{0}=45$ and $e_{0}=59$ (Fig. 6b). Figure 7 shows that the capillary hysteresis exists in the range of suction between the air-entry value $s_{\mathrm{eH}}$ and the suction of convergence $s_{\text {conv }}$. Provided that the air-entry value depends strongly on the void ratio, the size of the hysteresis differs significantly from one density to another. The shape of the obtained hysteresis is qualitatively consistent with the experimental results of Romero (1999) who performed drying-wetting cycles on a similar material. The simulation of a complete drying-wetting cycle also better illustrates the implications of the parameters of the model. If the calibration of the retention model is made on the basis of a drying test only, the elastic modulus $K_{\mathrm{H}}$ and the reference drying yield suction $s_{\mathrm{DI}}$ may be arbitrarily calibrated to best fit the experimental data using the multiple slopes featured in the model. But the wetting process shows that the size and shape of the hysteresis are also mostly driven by those two parameters, in which case attention must be paid to the hysteresis aperture and slope of the scanning lines for their calibration (Nuth and Laloui 2008). 
The proposed model thus constitutes a noteworthy alternative to conventional nonlinear elastic models. It makes use of a number of physical parameters with straightforward determination, and can readily feature the capillary hysteresis without any supplementary parameter. The response of the model relies at any time on information on the void ratio, the quality of which will have a direct effect on the prediction of the retention behaviour.

\section{Conclusion}

This paper reports experimental investigations and constitutive modelling of water retention phenomena in soils involving deformation effects. The results from two exhaustive experimental campaigns on the retention behaviour of a granular soil and a clayey soil were synthesized and analyzed. The results were presented through the variation of the degree of saturation, the void ratio, and the water content with respect to suction to get the complete information on the effect of suction loading on volumes of water and voids. These results highlight that the two soils studied had some features of behaviour in common. The void ratio was noticed to exert a clear influence on the air-entry value and the overall shape of the retention curves. In the plane of water content versus suction, from a certain suction value, the retention curves corresponding to different densities of the same soil converge and become unique. The conclusions made on the experimental data were conceptualized into a modelling framework accounting for the evolution of the degree of saturation as a function of suction and deformations. The proposed retention model makes use of the theory of elastoplasticity, inherited from a reference, hysteretic constitutive model. The calibration of the model requires an experimental retention curve for two initial void ratios. Finally, to analyze in detail the water retention behaviour of granular and clayey materials and to prove the model's ability to reproduce the behaviour of different materials, the experimental results were used for validation of the model.

\section{References}

Airò Farulla, C., Ferrari, A., and Romero, E. 2010. Volume change behaviour of a compacted scaly clay during cyclic suction changes. Canadian Geotechnical Journal, 47(6): 688-703. doi:10.1139/T09-138.

ASTM. 2006. Standard practice for classification of soils for engineering purpose (Unified Soil Classification System). American Society of Testing and Materials, West Conshohocken.

Cardoso, R., Romero, E., Lima, A., and Ferrari, A. 2007. A comparative study of soil suction measurement using two different high-range psychrometers. In 2nd International Conference on Mechanics of Unsaturated Soils,Weimar, Germany. March 2007. Edited by T. Schanz. Springer-Verlag, Berlin. pp. 79-93.

Cuisinier, O., and Laloui, L. 2004. Fabric evolution during hydromechanical loading of compacted silt. International Journal for Numerical and Analytical Methods in Geomechanics, 28(6): 483-499. doi:10.1002/nag.348.

D'Onza, F., Gallipoli, D., Wheeler, S., Casini, F., Vaunat, J., Khalili, N., Laloui, L., Mancuso, C., Masin, D., Nuth, M., Pereira, J.-M., and Vassallo, R. 2010. Benchmark of constitutive models for unsaturated soils. Géotechnique, 61(4): 283302. doi:10.1680/geot.2011.61.4.283.

Ferrari, A. 2007. Caratterizzazione meccanica di un'argilla a scaglie compattata non satura: effetti della suzione sulla resistenza al taglio. Ph.D. thesis, Universitá degli Studi di Palermo.

Fleureau, J.-M., Verbrugge, J-C., Huergo, P.J., Gomes Correia, A., and Kheirbek-Saoud, S. 2002. Aspects of the behaviour of compacted clayey soils on drying and wetting paths. Canadian Geotechnical Journal, 39(6): 13411357. doi:10.1139/t02-100.

Fredlund, D.G., and Pham, H.Q. 2007. Independent roles of the stress state variables on volume-mass constitutive relations. In Proceedings of the 2nd International Conference on Mechanics of Unsaturated Soils. Springer. pp. 1223-1256.

Gallipoli, D., Wheeler, S., and Karstunen, M. 2003. Modelling the variation of degree of saturation in a deformable unsaturated soil. Géotechnique, 53(1): 105-112. doi:10.1680/geot.2003.53.1.105.

Kawaï, K., Karube, D., and Kato, S. 2000. The model of water retention curve considering effect of void ratio. In Unsaturated Soil for Asia. Balkema, Rotterdam. pp. 329-334.

Koliji, A., Laloui, L., Cusinier, O., and Vulliet, L. 2006. Suction induced effects on the fabric of a structured soil. Transport in Porous Media, 64(2): 261-278. doi:10.1007/s11242-005-3656-3.
Mašín, D. 2010. Predicting the dependency of a degree of saturation on void ratio and suction using effective stress principle for unsaturated soils. International Journal for Numerical and Analytical Methods in Geomechanics, 34: 73-90. doi:10.1002/nag.808.

Mbonimpa, M., Aubertin, M., Maqsoud, A., and Bussière, B. 2006. Predictive model for the water retention curve of deformable clayey soils. Journal of Geotechnical and Geoenvironmental Engineering, 132:1121-1132. doi:10.1061/ (ASCE)1090-0241(2006)132:9(1121).

Miller, C.J., Yesiller, N., Yaldo, K., and Merayyan, S. 2002. Impact of soil type and compaction conditions on soil water characteristic. Journal of Geotechnical and Geoenvironmental Engineering, 128: 733-742. doi:10.1061/(ASCE)10900241(2002)128:9(733).

Miller, G.A., Khoury, C.N., Muraleetharan, K.K., Liu, C., and Kibbey, T.C.G. 2008. Effects of soil skeleton deformations on hysteretic soil water characteristic curves: experiments and simulations. Water Resources Research, 44: W00C06 doi:10.1029/2007WR006492.

Nuth, M., and Laloui, L. 2008. Advances in modelling hysteretic water retention curve in deformable soils. Computers and Geotechnics, 35(6): 835-844. doi: 10.1016/j.compgeo.2008.08.001.

Nuth, M., Laloui, L., and Schrefler, B.A. 2010. Analysis of compaction phenomena due to water injection in reservoirs with a three-phase geomechanical model. Journal of Petroleum Science and Engineering, 73: 33-40. doi:10.1016/j.petrol. 2010.05.005.

Olchitsky, E. 2002. Couplage hydromécanique et perméabilité d'une argile gonflante non saturée sous sollicitations hydriques et thermiques. Ph.D. thesis, École Nationale des Ponts et Chaussées, Paris.

Parent, S.E., Abdolahzadeh, A.M., Nuth, M., and Cabral, A.R. 2011. Hydraulic conductivity and water retention curve of highly compressible materials. In Developments in hydraulic conductivity research. Edited by O. Dikinya. InTech. pp. 71-110.

Péron, H., Hueckel, T., and Laloui, L. 2007. An improved volume measurement for determining soil water retention curves. Geotechnical Testing Journal, 30(1): 1-8. doi:10.1520/GTJ100167.

Romero, E. 1999. Characterisation and thermo-hydro-mechanical behaviour of unsaturated boom clay: experimental study. Ph.D. thesis, Universitat Politechnica de Catalunya.

Romero, E., and Vaunat, J. 2000. Retentions curves of deformable clays. In Experimental evidence and theoretical approaches in unsaturated soils. Edited by A. Tarantina and C. Mancuso. In Proceedings of Experimental Evidence and Theoretical Approaches in Unsaturated Soils, International Workshop on Unsaturated Soils, Trento, Italy. Balkema: Rotterdam. pp. 91-106.

Romero, E., DellaVecchia, G., and Jommi, C. 2011. An insight into the water retention properties of compacted clayey soils. Geotechnique, 61(4): 313-328. doi:10.1680/geot.2011.61.4.313.

Salager, S. 2007. Etude de la retention d'eau et de la consolidation des sols dans un cadre thermohydro-mécanique. Ph.D. thesis, Université Montpellier 2, Montpellier.

Salager, S., El Youssoufi, M.S., and Saix, C. 2007. Experimental study of the water retention curve as a function of void ratio. In Proceedings of the International Conference Geo-Denver, Denver.

Salager, S., ElYoussoufi, M.S., and Saix, C. 2010. Definition and experimental determination of a soil-water retention surface. Canadian Geotechnical Journal, 47(6): 609-622. doi:10.1139/T09-123.

Salager, S., Rizzi, M., and Laloui, L. 2011.An innovative device for determining the soil water retention curve under high suction at different temperatures. Acta Geotechnica, 6(3): 135-142. doi:10.1007/s11440-011-0141-8.

Sugii, T., Yamada, K., and Kondou, T. 2002. Relationship between soil-water characteristic curve and void ratio. In Proceedings of the 3rd International Conference on Unsaturated Soils. Swets and Zeitlinger. Vol. 1, pp. 209-214.

Tarantino, A. 2009. A water retention model for deformable soils. Géotechnique, 59(9): 751-762. doi:10.1680/geot.7.00118.

Tarantino, A., and Tombolato, S. 2005. Coupling of hydraulic and mechanical behaviour in unsaturated compacted clay. Géotechnique, 55(4): 307-317. doi: 10.1680/geot.2005.55.4.307.

Vanapalli, S.K., Fredlund, D.G., and Pufahl, D.E. 1999. The influence of soil structure and stress history on the soil-water characteristics of a compacted till. Géotechnique, 44: 892-898. doi:10.1680/geot.1999.49.2.143.

Verbrugge, J.C., and Fleureau, J.M. 2002. Bases expérimentales du comportement des sols non saturés. In Mécanique des sols non saturés. Edited by $\mathrm{O}$. Coussy and J.M. Fleureau. Collection Mécanique et Ingéniérie des Matériaux, Hermès. pp. 69-112.

Viaene, P., Vereecken, H., Diels, J., and Feyen, J. 1994. A statistical analysis of six hysteresis models for the moisture retention characteristic. Soil Science, 157: 345-355. doi:10.1097/00010694-199406000-00003.

Zhou, J., and Yu, J.L. 2004. Influences affecting the soil-water characteristic curve. Journal of Zhejiang University Sciences, 6(8):797-804. 